\title{
Designing and Developing Video Lessons for Online Learning: A Seven-Principle Model
}

\author{
Chaohua Ou, David A. Joyner, and Ashok K. Goel \\ Georgia Institute of Technology
}

\begin{abstract}
Despite the ubiquitous use of instructional videos in both formal and informal learning settings, questions remain largely unanswered on how to design and develop video lessons that are often used as the primary method for delivering instruction in online courses. In this study, we experimented with a model of seven principles drawn from instructional design theories for designing and developing video lessons for an online graduate course. Feedback was collected from students through surveys on their perceptions of the effectiveness of the video lessons and the overall course quality for eight semesters. This paper shares the instructors' experience on the design and development of the video lessons as well as the survey findings. Implications of the findings for instructional design and future research are also discussed.
\end{abstract}

Keywords: artificial intelligence, instructional videos, online learning

Ou, C., Joyner, D.A., \& Goel, A.K. (2019). Designing and developing video lessons for online learning: A seven-principle model. Online Learning, 23(2), 82-104. doi:10.24059/olj.v23i2.1449

\section{Designing and Developing Video Lessons for Online Learning: A Seven-Principle Model}

Online education provided underserved students with increased access to education, and enrollments in online courses increased for the 14th straight year in 2016 (Seaman, Allen, \& Seaman, 2018). The rapid growth of online education has resulted in increasing interest in research on learning with instructional video (Poquet, Lim, Mirriahi, \& Dawson, 2018). In online courses, especially massive open online courses (MOOCs), video is often the primary method for delivering instruction (Hansch et al., 2015; Hollands \& Tirthali, 2014; Means, Toyama, Murphy, Bakia, \& Jones, 2009). Therefore, instructional video plays a significant role in online learners' learning experiences.

The widespread use of video in education during the past decade was made possible by the ready-to-use camera available in mobile devices, free streaming media hosting and sharing platforms, and recording studios available on many campuses. The rapid advancement of video technologies has made available a large variety of design options. According to Hansch et al. (2015), there are nine types of instructional videos, when defined by their affordances of learning, and there are 18 video production styles. Since courses vary greatly regarding subject matter, learning goals and objectives, and students, instructors have to make deliberate decisions on selecting and leveraging the most appropriate available technologies and resources to create videos that help students achieve desired learning outcomes. Hence, there is a growing need to develop 
research-based principles for designing instructional videos to support learning (De Koning, Hoogerheide, \& Boucheix, 2018; Hansch et al., 2015; Kay, 2012; Poquet et al., 2018).

Many of the research studies on instructional video draw heavily on instructional design theories, such as the cognitive theory of multimedia learning (Mayer, 2009) and cognitive load theory (Sweller, 1988), as a general framework for design considerations (Fiorella \& Mayer, 2018; Poquet et al., 2018). These studies have primarily focused on examining how information should be presented in a video and how learning from instructional video could be supported by engaging learners with exercises or other learning tasks (De Koning et al., 2018; Poquet et al., 2018). The findings of the studies have established several evidence-based principles for the effective design of instructional video regarding how to present visual and verbal information for optimal learning - for example, the segmenting principle, pacing principle, and signaling principle (De Koning et al., 2018; Fiorella \& Mayer, 2018). On the other hand, researchers are urged to investigate novel principles for designing instructional video because the "traditional" principles identified do not necessarily suffice as technological advancement enables new design possibilities and instructional video is used in new educational contexts (De Koning et al., 2018).

These established principles have been applied and tested in short-format instructional videos that mostly teach a procedure skill (e.g., how to carry out a medical procedure, conduct a software operation, or solve a math problem). They can stand alone or be part of a larger video lesson (Fiorella \& Mayer, 2018). In online courses that are structured by course topics, a short video is often used as part of a video lesson, as the course topic covered in the lesson does not necessarily demonstrate a how-to procedure and may require different types of instruction. Also, these video lessons often incorporate in-video quizzes or self-assessment questions to engage learners and help reinforce their learning (Hansch et al., 2015; Hollands \& Tirthali, 2014; Poquet et al., 2018). Therefore, the video lesson for online courses involves more than presenting content through a short video demo. It is a video-based learning module designed to achieve the learning objectives through sequenced content instructions and learning activities. Hence, there is a need to move beyond the existing design principles for multimedia presentations for procedural learning and explore new principles for the design and development of video lessons for online learning.

In this study, we applied seven principles drawn from instructional design theories to the design and development of video lessons for an online graduate course, integrating instructional presentation with instructional methods and sequencing. We examined the effectiveness of this model through the end-of-course student survey for eight semesters. This paper shares the survey findings as well as the instructors' experience of designing and developing the video lessons. Implications of the findings for instructional design and future research are also discussed.

\section{Review of Literature}

Several reviews have been conducted to synthesize and summarize the status, trend, and gap of the research on video-based learning (Fiorella \& Mayer, 2018; Hansch et al., 2015; Kay, 2012; Poquet et al., 2018).

Kay (2012) did a comprehensive review of 53 studies published between 2002 and 2011. The review indicates that, despite some challenges, students generally had positive affective and cognitive attitudes toward the use of videos to support learning. There was also evidence supporting the positive impact of videos on students' study habits and learning performance. 
Nonetheless, the author noted that the studies reviewed rarely described the details of the videos used - for example, the number of the videos, the length of the videos, and the content presentation in the videos. Without such information, it is impossible to generate a set of proven guidelines for designing effective instructional videos. Therefore, the author called for further research on pedagogical strategies for using videos and how the quality and design of videos affects learning.

The proliferation of MOOCs in recent years and the use of video as the primary means for delivering instruction has generated interest in using large-scale learning analytics from MOOCs to explore how students interact with videos (Chen et al., 2016; Guo, Kim, \& Rubin, 2014; Kim et al., 2014a; Kim et al., 2014b; Li, Kidzinski, Jermann, \& Dillenbourg, 2015; Sinha, Jermann, Li, \& Dillenbourg, 2014). The researchers examined students' video interaction patterns and explored how to leverage the patterns to provide insights for designing videos for better student engagement. However, their findings are not completely transferable to general use, as the limitations of their studies point out that

- video interaction cannot accurately represent learners' real behavior (e.g., they may play a video but not watch it);

- video interaction might depend on other pedagogical methods in the courses, such as online discussions, assignments, and quizzes; and

- MOOC learners have different learning goals, which affect their learning behavior, and they might not be representative of students who take other types of online courses.

Researchers also argued that measuring student engagement through analyzing clickstream data and viewing statistics may not be an effective proxy for measuring learning, because engagement should not be conflated with learning (Hansch et al., 2015). On the other hand, the review conducted by Poquet et al. (2018) indicates that very few of the video interaction studies in MOOC contexts were grounded in educational or psychological theory. There is a need to bridge the gap between the video interaction analysis and the use of established psychological measures to strengthen insights on the impact of video interaction on learning.

Hansch et al. (2015) examined how videos were designed, produced, and used in MOOCs, specifically concerning pedagogy and cost, through observing 20 MOOCs and interviewing 12 practitioners in the field of educational video production. Their findings include the following:

- video is used mainly for content delivery in nearly all MOOCs, even though there is little research on the effectiveness of video as a pedagogical tool for online learning; and

- expensive production techniques are often used in video production despite a lack of evidence that a high production style leads to better learning outcomes.

The authors recommended that, when making design decisions, practitioners should do the following:

- think carefully about whether video is the most appropriate medium for instruction,

- make the best of video as a medium by selecting a video production style that is appropriate for stated objectives and outcomes, and

- consider both lightweight and DIY approaches to video production.

Finally, the authors called for more research on the pedagogical effectiveness of video as well as new and better metrics that measure how people learn from video. They encouraged practitioners to share their experiences concerning creative approaches to video production and use. 
Poquet et al. (2018) reviewed 178 empirical studies published from 2007-2017. The results of the review provide a preliminary overview of the effects of videos on diverse learning outcomes, including the effect of manipulating video presentation, learning tasks, and the way content is structured and communicated. The review also offers a high-level overview of the trends and patterns of manipulation in the research studies, indicating that they draw heavily on the cognitive theory of multimedia learning (Mayer, 2009) and cognitive load theory (Sweller, 1988) as general frameworks for design considerations. However, the authors do not come to any clear and substantial conclusion indicating what works and what doesn't. The diversity of video formats, purposes, and contexts in the studies makes it a challenge to offer any concise recommendations for practice. Consequently, they support the first two recommendations mentioned above from Hansch et al. (2015), in addition to offering a few very general suggestions, such as presenting content that can challenge prior knowledge, presenting problem-solving activities, conducting immediate quizzing, and engaging learners with active learning tasks. In the end, the authors call for more research on learning analytics, multimodal analytics, and collaborative tasks for video viewing to advance understanding of video-based learning and refine existing theories.

Fiorella and Mayer (2018) identified what works and what does not work with instructional video based on previous research findings. Two techniques can improve learning outcomes with instructional video: (1) segmenting - that is, breaking a video into smaller and meaningful segments with learner control - and (2) mixed perspective - that is, filming from a mix of firstperson and third-person perspective. Features that do not work with instructional video include matching the gender of the instructor to the gender of the learner, showing the instructor's face on the screen, inserting pauses in the video, and adding practice without feedback. Built on this established knowledge base, current research on video-based learning is moving in three directions (De Koning et al., 2018): (1) extending "traditional" design principles; (2) exploring novel design principles; and (3) investigating the role of personal attributes in learning with instructional video.

The need to explore novel design principles arises because rapid technological advancement enables new possibilities for creating instructional videos, and they are being used in an increasing number of subject domains or contexts that have not been studied in previous research. The established design principles mainly focus on how to present information effectively in video to optimize procedural learning. However, they do not necessarily apply to the design of video lessons in online courses, as they may cover more diverse course topics that teach different skills and often integrate content with learning activities to help students achieve learning outcomes. As more and more students are taking online courses nowadays and relying heavily on video lessons for their learning, it is necessary to explore and identify new design principles for effective video-based learning in this context.

\section{A Seven-Principle Model for Designing and Developing Video Lessons}

The recommendations for moving beyond the existing design principles involve "moving toward better aligning instructional methods, learning materials, process measures, and learning outcome measures" (Fiorella \& Mayer, 2018, p. 469). In this study, we explored the design and development of video lessons for an online graduate course by integrating instructional presentation with instructional methods and instructional sequence. Instructional methods are ways to support and facilitate human learning or development (Reigeluth, 1999), and instructional sequence refers to the order of presentation of instruction (Van Patten, Chao, \& Reigeluth, 1986). 
Both are major components of instructional design — decisions need to be made on which methods should be used to teach under given conditions and in what order the instruction should be given (Morrison, Ross, Kemp, \& Kalman, 2012; Reigeluth, 1999; Van Patten, Chao, \& Reigeluth, 1986). Two authors of this paper, Goel and Joyner, employed seven principles drawn from instructional design theories as the guidelines for designing and developing video lessons for an online course on artificial intelligence. This seven-principle model is comprised of four instructional methods, two principles for instructional presentation, and one principle for instructional sequence (Figure $1)$.

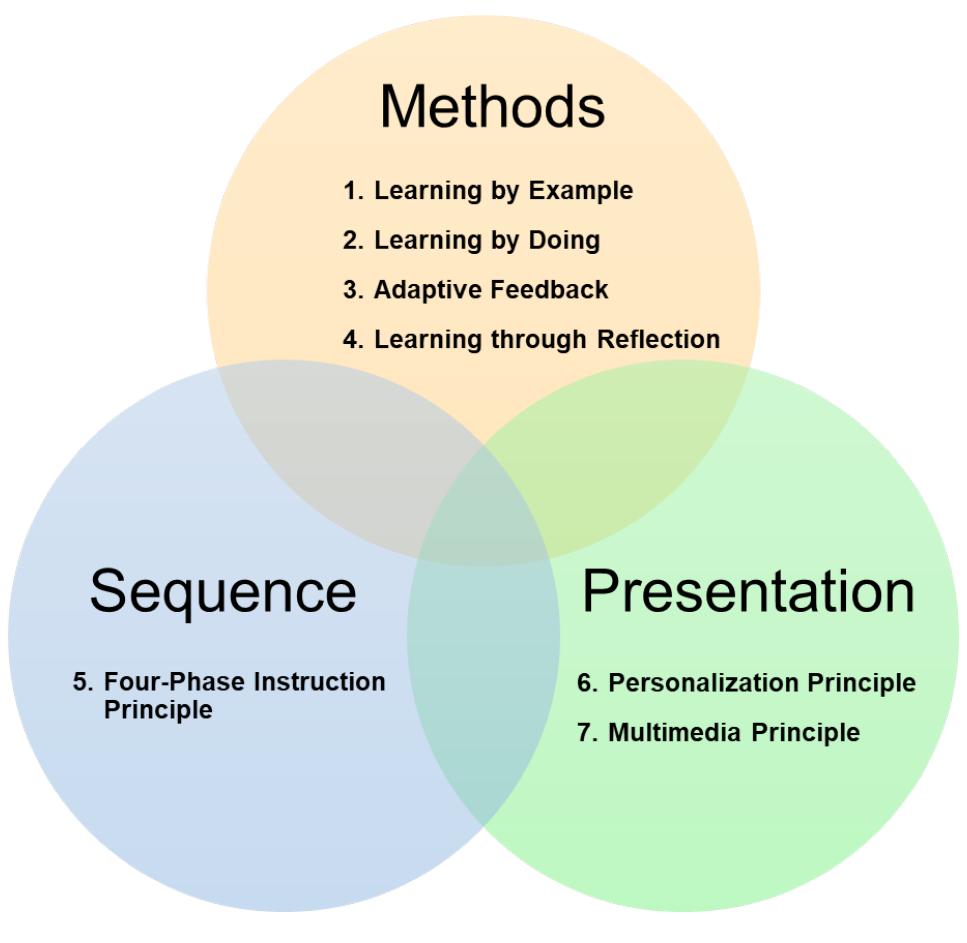

Figure 1. A seven-principle for designing and developing video lessons.

\section{Methods}

The course, Knowledge-Based Artificial Intelligence (KBAI), is a foundational course in artificial intelligence and part of an online master of science program in computer science at the Georgia Institute of Technology. The goals of the class were to understand the tasks that KBAI addresses, the methods it employs to address those tasks, the systems that comprise those methods and tasks, and the relationship between creating those systems and understanding human cognition. To demonstrate mastery of these learning goals, students build systems that address complex problems, and then they reflect on the relationship between those systems and human cognition (Goel \& Joyner, 2016, 2017). The following four instructional methods are used to facilitate students' learning with the video lessons and help students achieve the learning goals:

- Learning by example: Learning occurs when learners actively construct their knowledge by interpreting their experiences. Therefore, instruction should consist of experiences that facilitate knowledge construction. Presenting examples (related cases) supports learning 
by providing a representation of experiences that learners have not had (Jonassen, 1999). Video is an excellent medium for presenting examples, as they can be demonstrated on the screen through visuals, animations, and video recordings, accompanied by audio.

- Learning by doing: Research studies consistently suggest that using active learning activities in teaching leads to better student attitudes and better learning outcomes when compared to teaching with traditional lecture approaches (Prince, 2004). Active learning engages students in two ways: doing things and thinking about the things they are doing (Bonwell \& Eison, 1991). Interleaving sequences of videos with interactive exercises gives students opportunities to interact with the content materials.

- Adaptive feedback: Many video lessons in online courses encourage active learning by offering exercises for students to practice. Research indicates that practice without feedback does not help students learn (Fiorella \& Mayer, 2018). Students usually get feedback on whether their answer is correct or incorrect once they submit it. They may be given opportunities to retry if they do not get it right. Although this automated feedback works well with questions that have standardized answers, it still lacks the just-in-time feedback and guidance that instructors in the classroom can provide. Adaptive feedback could be a good solution for providing feedback in an asynchronous online learning environment, as it not only verifies the correctness of an answer but also provides different information for different answers (Bimba et al., 2017; Dempsey \& Sales, 1993; Le, 2016).

- Learning through reflection: Reflection, according to Dewey (1993), is an "active, persistent and careful consideration of any belief or supposed form of knowledge in the light of the grounds that support it, and further conclusions to which it tends" (p. 9). Reflection is related to learning in that it encourages metacognition and enables learning from representing learning (Moon, 1999). Various reflection activities can be integrated into the curriculum: for example, learning journals, logs, diaries, peer and self-assessments, and portfolios.

\section{Sequence}

Generally speaking, course instruction is sequenced at macro and micro levels. Macro sequencing structures the teaching of some different but related content ideas, such as topics for a course. Micro sequencing structures the order of presenting the generalities, examples, and practices for teaching a particular course topic. Different micro sequencing may result in different learning outcomes (Reigeluth \& Keller, 2009; Van Patten et al., 1986). While sequencing depends on many variables, such as content, learner, and outcome, many instructional models suggest that the most effective learning products or environments are those that are problem centered and include four phases of instruction: (1) activation of prior experience, (2) demonstration of skills, (3) application of skills, and (4) integration of these skills into real-world activities (Merrill, 2002, 2007). This four-phase instruction principle is adopted and applied for sequencing the video lessons, creating a coherent and dynamic structure that guides students through the learning process.

\section{Presentation}

It is very important to select a video production that is appropriate for learning objectives and content presentation (Hansch et al., 2015; Poquet et al., 2018). The production style of instructional videos varies widely, and researchers have tried to identify and classify different 
types of production style (Chorianopoulos, 2018; Hansch et al., 2015; Santos-Espino, AfonsoSuárez, \& Guerra-Artal, 2016). These studies illustrate many different options for visual presentation of course content through videos. More importantly, they define the two dimensions of classification scheme: human embodiment (e.g., talking head, voice-over, animated human, digital avatar, robot) and instructional media (e.g., slides, handwriting, graphics, animation, screencast). The instructors extended the following two multimedia learning principles regarding the human embodiment and instructional media for instructional presentation:

- Personalization principle: The personalization principle of multimedia learning suggests three instructional approaches to promote learning: using conversational rather than formal style, using effective on-screen coaches, and making the author (instructor) visible (Clark $\&$ Mayer, 2016; Mayer, 2014). The psychological reason for these approaches is to prime a social presence in the learners that encourages them to engage with the on-screen coach/author/instructor as a social conversational partner, resulting in deeper cognitive processing during learning (Clark \& Mayer, 2016; Mayer, 2009, 2014). While displaying an instructor's talking head is one of the common practices to apply the personalization principle in instructional videos, research findings indicate that having the instructor's face on the screen is not an effective practice in instructional video (Fiorella \& Mayer, 2018). The instructors decided to experiment with a more conversational and interactive teaching style: team teaching. Both of the instructors appeared on the screen and discussed the course topics in some of the videos. They were hoping that the interactive conversation/discussion format of teaching would help build a connection between the instructors and the students, stimulating their interest and engaging them as well.

- Multimedia principle: Many instructional videos, such as those hosted on Khan Academy (khanacademy.org) or Udacity (udacity.com), display instructors writing and gesturing on a digital whiteboard. The video produced from this type of tablet capture, along with the instructor's voice-over, has recreated natural features of an in-person classroom, where instructors would use a physical whiteboard or a computer projector for presentation. The instructors made a major change to this style by using prepared visuals instead of livedrawn text. There are three main reasons for doing this. (1) Using visuals, such as graphics, charts, or animation, is a strategic application of the multimedia principle and modality principle: People learn better when content is presented with both words and graphics rather than words alone, and words should be presented as audio narration rather than onscreen text (Clark \& Mayer, 2016; Mayer, 2009, 2014). (2) Using prepared visuals gives more time for iteration and refinement of visuals. The instructor and course developer went through numerous iterations scripting course content, discussing optimal visualizations, and prototyping them before recording, thus improving the finished product beyond what could be generated live while recording. (3) It reduces cognitive load during the recording process. Instructors may focus all their cognitive resources on narrating the course content to students rather than attending live to the visual layout of the screen, the selection of pen colors for certain types of content, or the legibility of handwriting. 


\section{Context of the Study}

The online KBAI course comprises 26 video lessons, with the first lesson giving students an overview of the course and the second lesson introducing students to KBAI. Each of the next 23 lessons covers a KBAI topic. The last lesson is a course wrap-up. Each of the video lessons lasts approximately 60 minutes. However, the lesson is broken into video clips to fit the individual topics of the lesson, with the length ranging from 1 to 5 minutes. These sequences of video clips are interwoven with interactive exercises, and the exercises are equipped with a set of intelligent tutors that give students adaptive feedback when they submit their responses to the exercises (Goel \& Joyner, 2016, 2017).

Table 1 summarizes how the video lessons are designed by incorporating the four instructional methods and how they are sequenced based on the principle of four-phase instruction, followed by detailed descriptions of each phase.

Table 1.

The Integrated Design of Video Lessons in KBAI

\begin{tabular}{|c|c|c|c|}
\hline $\begin{array}{l}\text { Instructional } \\
\text { phase }\end{array}$ & $\begin{array}{l}\text { Component of } \\
\text { video lesson }\end{array}$ & $\begin{array}{l}\text { Instructional } \\
\text { methods }\end{array}$ & Video example \\
\hline Activation & Preview of the lesson & $\begin{array}{l}\text { Learning through } \\
\text { reflection }\end{array}$ & $\underline{\text { bit.ly/kbai-preview }}$ \\
\hline Demonstration & $\begin{array}{l}\text { Presentation and } \\
\text { discussion } \\
\text { of lesson topics }\end{array}$ & Learning by example & $\frac{\text { bit.ly/kbai-presentation }}{\underline{\text { bit.ly/kbai-discussion }}}$ \\
\hline Application & $\begin{array}{l}\text { Exercises } \\
\text { Exercise solutions } \\
\text { Assignments }\end{array}$ & $\begin{array}{l}\text { Learning by doing } \\
\text { Adaptive feedback }\end{array}$ & 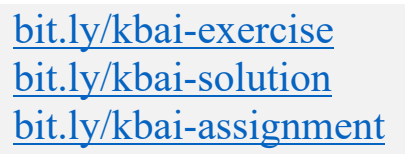 \\
\hline Integration & $\begin{array}{l}\text { Wrap-up } \\
\text { The cognitive connection } \\
\text { Reflection }\end{array}$ & $\begin{array}{l}\text { Learning through } \\
\text { reflection }\end{array}$ & $\frac{\underline{\text { bit.ly/kbai-wrapup }}}{\text { bit.ly/kbai-connection }}$ \\
\hline
\end{tabular}

1. Activation: The instructors started each lesson with a preview, which introduced students to the topics to be discussed. They also directed students to recall and relate their prior knowledge and relevant experience that can be used as a foundation for the new knowledge.

2. Demonstration: The instructors demonstrated KBAI methods, tasks, and applications by using various real-life examples, presented with visuals such as graphics, tablet capture, illustration, animation, and simulation.

3. Application: Interactive exercises were embedded in the video lessons so that students could practice and reinforce what they learned from the demonstrations. Figure 2 is a screenshot of an example of the exercises in which students are asked to fill 24 boxes to represent the possible next state of a problem in accordance with rules provided. The exercise is provided with adaptive feedback from intelligent tutors. The tutor operates first by examining whether the input to the problem even makes sense. If not, the tutor supplies feedback on the type of input it will understand, guiding students along to the closed input set that it can process. Then, once it understands the input, it examines whether that input is valid. If the input is valid according to the rules of the exercise, it moves on to checking 
correctness. For some exercises, the tutor also checks to see if the answer is the best answer. Figure 3 shows two pieces of feedback a student may receive from the tutor based on his or her input. The instructors also discussed how the new knowledge could be applied in the real world. They got students involved by asking students to answer questions after the discussion. The instructors then gave students an assignment on how to apply what they learned to solve a problem.

4. Integration: The instructors wrapped up the lesson by giving a recap of the topics discussed and connected them with the topics to be covered in the next lesson. Then, they examined the relationship between the topics and human cognition. Finally, they brought the lesson to closure by asking students to reflect and write down what they learned from the lesson.

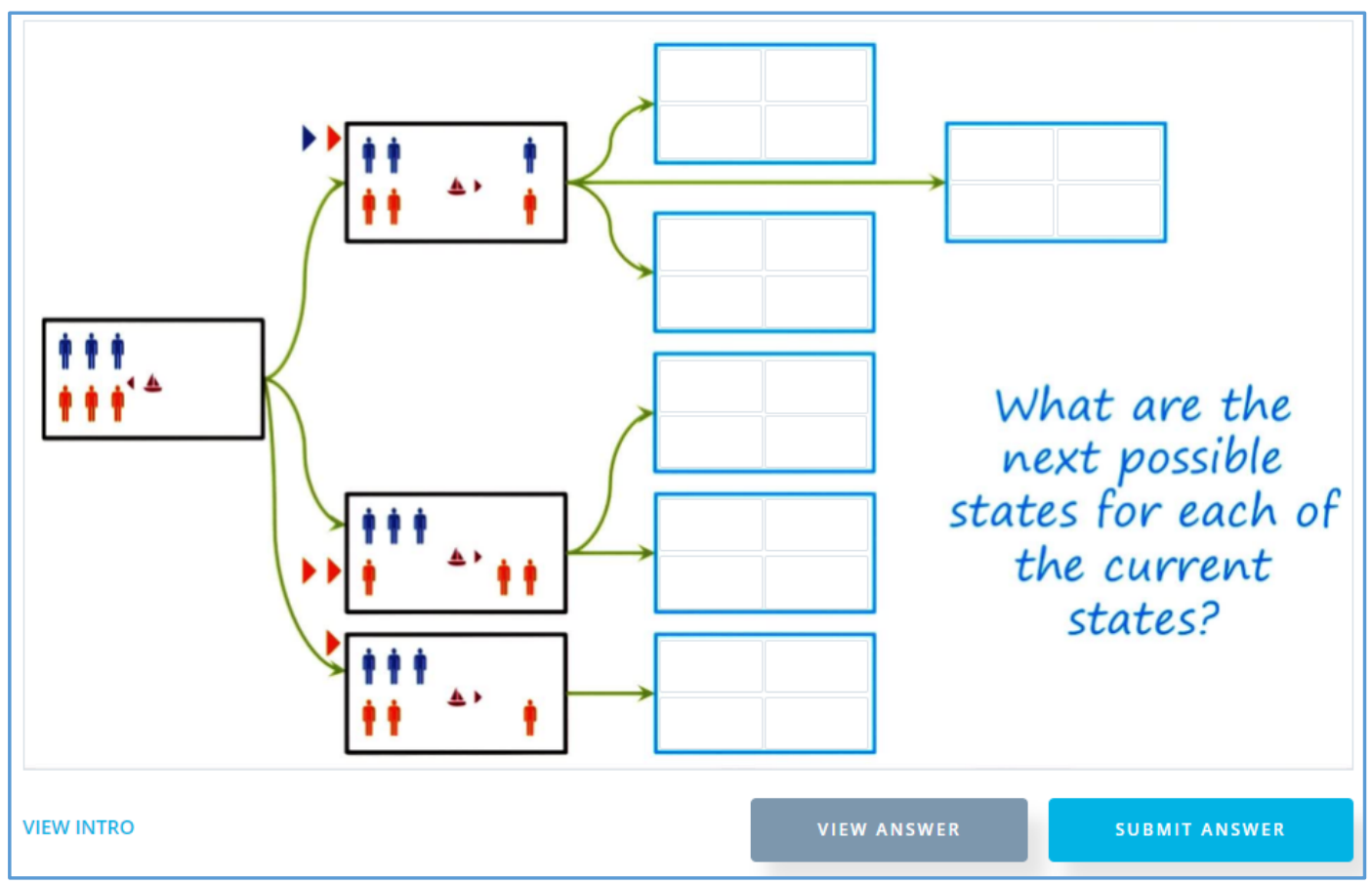

Figure 2. An example of exercises in the video lessons (Goel \& Joyner, 2017). 
Designing and Developing Video Lessons for Online Learning: A Seven-Principle Model

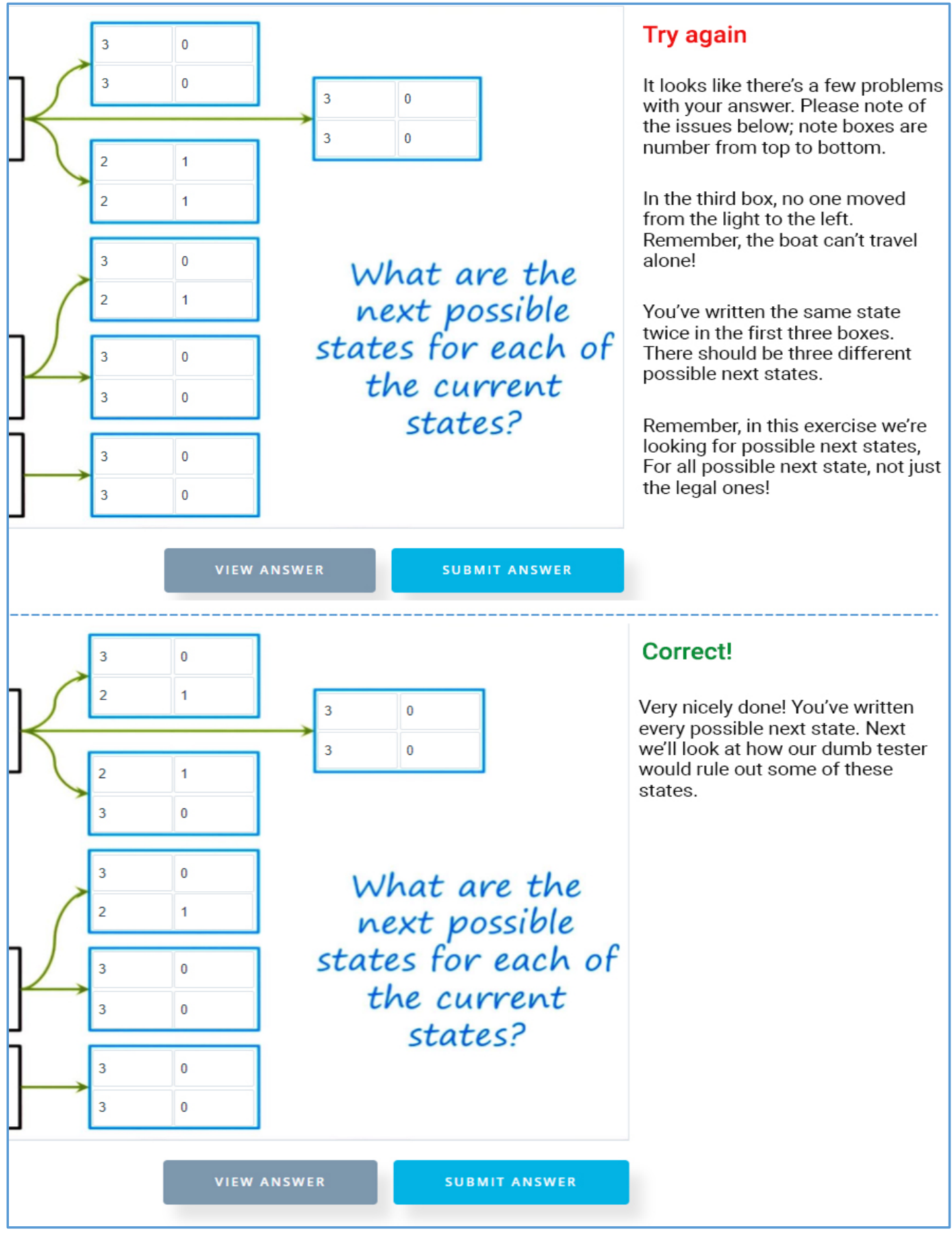

Figure 3. An example of feedback provided by the intelligent tutor (Goel \& Joyner, 2017). 


\section{Methods}

This study was designed to address the following two research questions, and survey research was the primary method for collecting and analyzing data to address them:

- What are student perceptions of the video lessons developed with a seven-principle model?

- To what extent are student perceptions of the video lessons related to their perceptions of the course effectiveness?

Students were invited to take two surveys: (1) a start-of-course survey, which was conducted at the beginning of the semester to help the instructors get to know the students, and (2) an end-ofcourse survey, which was conducted at the end of the semester to gauge students' opinions on course progress and feedback on various course elements. Both surveys were administered through the learning management system used at the university. Although students were required to $\log$ in with their university user account and password, the survey was anonymous. The instructors encouraged the students to participate in the survey by communicating to them through the course syllabus and emails that their feedback would help improve the course and the new online program. Participation was voluntary, and no incentives were offered for taking part in the research study.

\section{Survey Instrument}

Data on student perceptions of the effectiveness of the video lesson and the course was collected through the end-of-course survey. The survey included questions asking students for feedback on course progress and various course elements, such as the video lessons, online discussions, peer feedback, assignments, projects, and so on. Only the questions on the effectiveness of the video lessons and the course are reported in this study. Questions on other course elements are not included.

We have not yet found any tested survey instrument specifically for assessing the effectiveness of instructional video. While there are established student survey instruments assessing the effectiveness of instruction in traditional classroom teaching settings (e.g., Aleamoni, 1978; Marsh, 1982), the extent to which they can be transplanted to the new context of online instruction is questionable, as the instruments were developed when online learning environments were almost nonexistent (Theall \& Feldman, 2007). On the other hand, the instrument developed specifically for online teaching (e.g., Bangert, 2006) was intended to assess multiple instructional dimensions. Thus, its use is limited for measuring the effectiveness of video lessons specifically. Nevertheless, various factors or dimensions representing characteristics of effective instruction have been identified in research on student ratings of instructional effectiveness (Bangert, 2006; Cohen, 1981; Feldman, 2007; Marsh, 1991). The factors concerning instructional presentation, learning exercises, and feedback, which are core components of the video lessons, were selected and used to guide the development of a set of four questions for assessing the effectiveness of the video lessons. The selected factors are (1) clarity and understandableness, (2) active learning, (3) feedback, and (4) learning/value.

Students were asked to rate their agreement with the following four statements regarding the video lessons, using a seven-point Likert scale ranging from 1 (strongly disagree) to 7 (strongly agree):

1. The lectures are informative and easy to understand.

2. The exercises provided during the lectures kept me engaged.

3. The feedback I received from the exercises enhanced my understanding of the lesson.

4. Overall, the video lessons were valuable in helping me learn. 
A reliability analysis (Cortina, 1993; Cronbach, 1988) was carried out by using all responses to these four statements from the students who completed the survey $(N=1,242)$ to measure the internal consistency of the four-item scale on the effectiveness of the video lessons. Cronbach's alpha showed that the scale reaches a high level of internal consistency, $\alpha=.828$. All four items appeared to be worthy of retention. Deleting any of them would result in a decrease in the alpha (see Table 2). As such, all items are included in the scale for the measurement.

Students were also asked to rate the overall quality of the course, using a seven-point Likert scale ranging from 1 ( $b a d$ ) to 7 (excellent), for the purpose of examining whether the students' perceived effectiveness of the video lessons will predict their perceptions of the course effectiveness.

In addition to the quantitative data, qualitative data were collected to get deeper insights into student perceptions: what they like about the video lessons and what changes they would like to see made to the video lessons. The rationale for this approach is that the collection and analysis of both quantitative and qualitative data can address the research questions with sufficient breadth and depth (Morgan, 2014; Teddlie \& Tashakkori, 2009).

Table 2.

Reliability Analysis of the Four-Item Scale Measuring the Effectiveness of Video Lessons

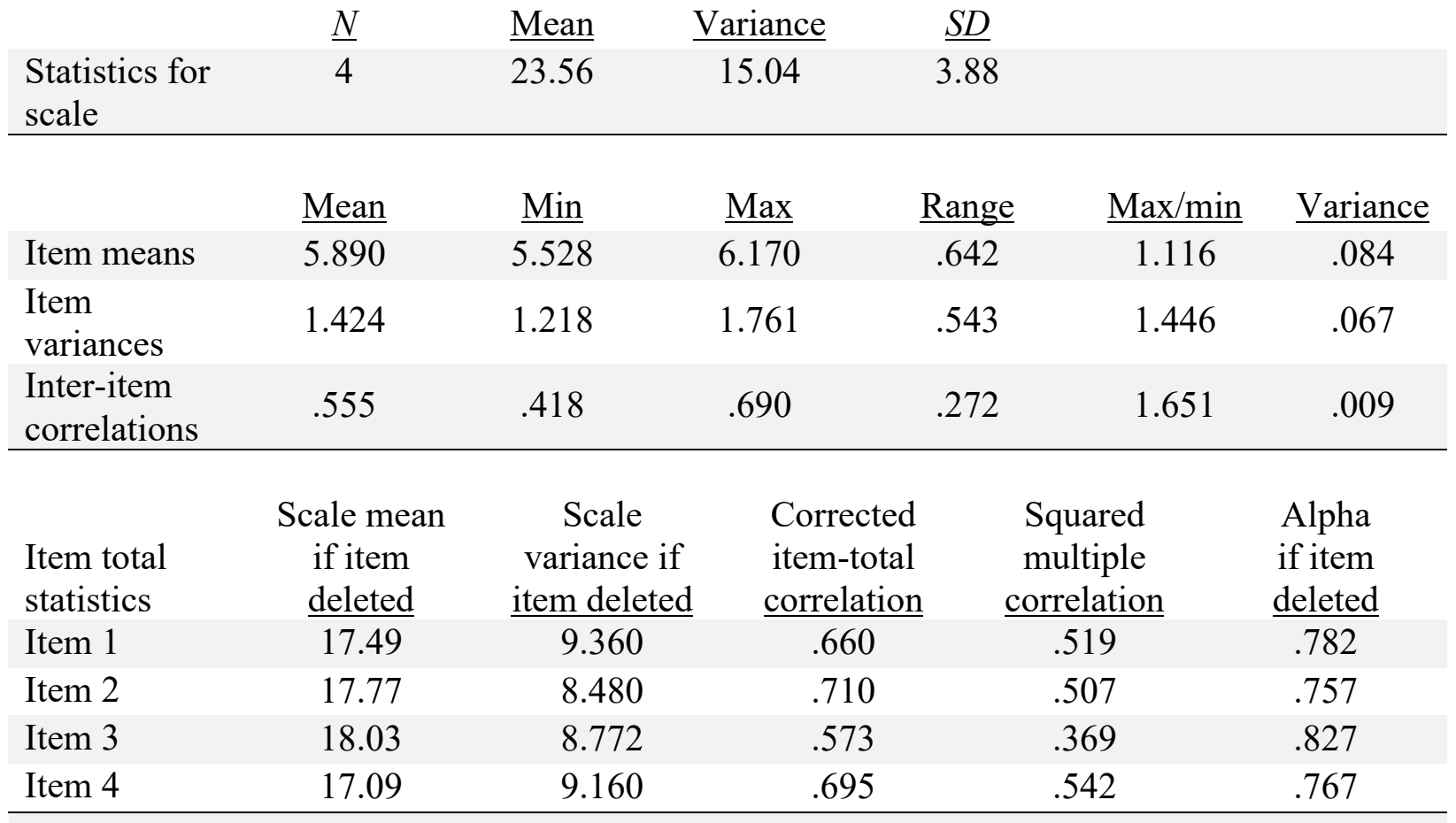

$\begin{array}{lll}\text { Reliability coefficient } & \text { Alpha } & \text { Standardized item alpha } \\ .828 & .833\end{array}$




\section{Participants}

The participants of the study were the 1,913 students who took the KBAI online course during the eight semesters from fall 2014 to spring 2017. A total of 1,670 completed the start-ofcourse survey for a response rate of $87 \%$. The survey asked demographic questions, including their age, gender, country of residence, and education. Students also reported their prior programming experience as a proxy for their existing programming skill. Students' programming experience seemed to be extensive but varied (see Table 3). These results indicate that more than half of the students were between the ages of 25 and 34 . Almost $90 \%$ of them were male, and almost $90 \%$ lived in the United States. Almost a quarter of students reported they are not native English speakers. All students had at least a bachelor's degree (as this is required for admission into the program), but 20\% had other graduate degrees, including master's or doctoral degrees.

Table 3.

Online KBAI Students' Demographics

\begin{tabular}{llrr}
\hline Demographics & & $N$ & $\%$ \\
Age & 18 to 24 & 234 & 14.0 \\
& 25 to 34 & 908 & 54.4 \\
& 35 to 44 & 379 & 22.7 \\
& 45 and above & 148 & 8.9 \\
\cline { 2 - 4 } Total & 1,669 & 100.0 \\
& Female & 206 & 12.4 \\
& Male & 1,454 & 87.1 \\
& Other & 4 & 0.2 \\
\cline { 2 - 4 } Country of residence & Total & 1,664 & 100.0 \\
& United States (U.S.) & 1,468 & 88.1 \\
& Outside of U.S. & 199 & 11.9 \\
\cline { 2 - 4 } First language & Total & 1,667 & 100 \\
& English & 1,266 & 76.3 \\
Highest prior education & Other languages & 393 & 23.7 \\
\cline { 2 - 4 } & Total & 1,659 & 100.0 \\
& Bachelor's degree & 1,311 & 78.7 \\
& Master's degree & 272 & 16.3 \\
& Doctoral degree & 81 & 4.9 \\
& Other & 2 & 0.1 \\
\cline { 2 - 4 } Yotal & 1,663 & 100.0 \\
Years of programming & 0 & 28 & 1.7 \\
& 1-2 & 328 & 19.8 \\
& 3-5 & 352 & 21.2 \\
& $6-10$ & 434 & 26.1 \\
& $11-15$ & 263 & 15.8 \\
\cline { 2 - 4 } & More than 15 & 255 & 15.3 \\
\cline { 2 - 4 } & Total & 1,660 & 100.0 \\
\hline
\end{tabular}




\section{Data Analysis}

Data collected from the Likert-scale questions were analyzed using descriptive and deferential statistics in SPSS. The descriptive statistics provide insights into students' perceptions of video effectiveness and course effectiveness. Regression analysis was performed to see how students' perceptions of the video lessons could predict their perceptions of course effectiveness.

Data collected from the open-ended questions were coded using thematic analysis (Braun \& Clark, 2006; Guest, MacQueen, \& Namey, 2011). The primary author and an independent rater coded the data by following the six steps below:

1. Familiarization with data: The data were imported into an Excel spreadsheet, and the researchers read and familiarized themselves with the data. Then they identified and labeled those that were not relevant. They were excluded from coding. Finally, the researchers worked together to identify and segment each response into different meaningful units.

2. Generating initial code: The researchers first coded a small set of responses together to get a mutual understanding of the coding. Then they coded another small set of data individually and got together to compare, discuss, and clarify the differences in their coding. They went back to code the rest of the data. The codes were recorded in separate columns, and percentage agreement between the two raters was calculated. The results indicate that interrater reliability was $89 \%$. After discussions, they reached an agreement and developed a list of codes across the data set.

3. Searching for themes: The researchers sorted and collated coded data extracts into themes.

4. Reviewing themes: The researchers reviewed the coded data extracts and revised inadequacies in the coding and themes.

5. Defining and naming themes: The researchers established and defined the themes.

6. Producing the report: The researchers put together the final analysis and write-up of the themes.

\section{Results}

\section{Student Perceptions of the Video Lessons: Effectiveness}

A total of 1,242 students completed the end-of-course survey for a response rate of $65 \%$. The results indicate students' ratings of the four statements on the video lessons were consistently high (see Table 4). More than $90 \%$ of the students - those who chose strongly agree, agree, or agree slightly - agreed that the video lectures were informative and easy to understand and that the video lessons were valuable in helping them learn. As for the in-lesson exercises, more than $80 \%$ of the students agreed that the exercises kept them engaged and that the exercise feedback they received enhanced their understanding of the lessons. 
Table 4

Students' Ratings of the Four Statements on the Video Lessons

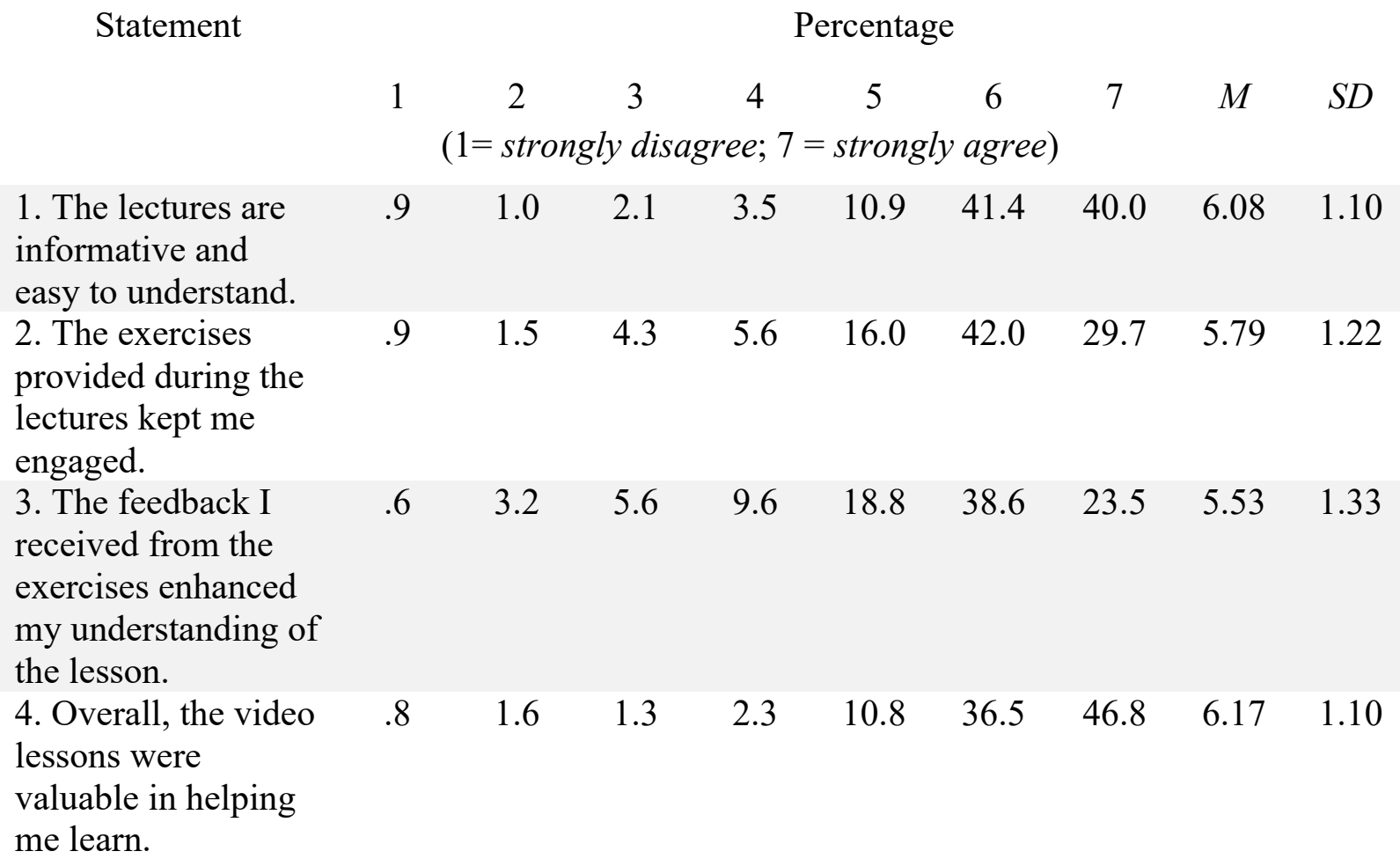

\section{Student Perceptions of the Video Lessons: Likes and Changes}

A total of 906 students responded to the question about what course elements they would like to see in other online courses. Among them, 173 (19\%) recommended the video lessons among various course elements. While some students said they liked the overall quality of the video lessons, other students state which elements of the video lesson they particularly liked. The coding results indicate that students liked the video lessons because of five major elements (see Table 5). 
Table 5

What Students Liked About the Video Lessons: Code, Explanation, and Illustrative Note

\begin{tabular}{|c|c|c|c|}
\hline Code & Frequency & Explanation & Illustrative note \\
\hline $\begin{array}{l}\text { Video } \\
\text { lectures }\end{array}$ & 41 & $\begin{array}{l}\text { Video lectures are } \\
\text { interactive, easy-to- } \\
\text { understand, } \\
\text { interesting, and } \\
\text { relevant. }\end{array}$ & $\begin{array}{l}\text { I liked the interactive lessons and the } \\
\text { basic examples that really helped } \\
\text { understand the concepts so they could be } \\
\text { applied later. }\end{array}$ \\
\hline $\begin{array}{l}\text { Exercises } \\
\text { and } \\
\text { feedback }\end{array}$ & 40 & $\begin{array}{l}\text { Exercises and } \\
\text { feedback are } \\
\text { interactive and } \\
\text { reinforce learning. }\end{array}$ & $\begin{array}{l}\text { KBAI had pretty decent mid-lesson } \\
\text { quizzes. I've found that most classes other } \\
\text { than a select few have had very poor } \\
\text { examples of these quizzes, with some } \\
\text { classes almost never using them. I find } \\
\text { them to be a huge improvement in lecture } \\
\text { quality as it not only keeps the student } \\
\text { engaged in an otherwise watch and listen } \\
\text { only environment, but enforces the } \\
\text { material during the lesson. }\end{array}$ \\
\hline $\begin{array}{l}\text { Overall } \\
\text { quality }\end{array}$ & 31 & $\begin{array}{l}\text { Video production and } \\
\text { course content were } \\
\text { excellent. }\end{array}$ & $\begin{array}{l}\text { The quality of teaching in the class videos } \\
\text { is the best I have seen so far (I have taken } \\
3 \text { other classes). I hope all classes are like } \\
\text { this. }\end{array}$ \\
\hline $\begin{array}{l}\text { Instructional } \\
\text { structure }\end{array}$ & 29 & $\begin{array}{l}\text { The instructional } \\
\text { structure guides } \\
\text { learning. }\end{array}$ & $\begin{array}{l}\text { I enjoyed the pragmatic order of each of } \\
\text { the series. Each has a preview, (content), } \\
\text { then a wrap-up, cognitive connection, then } \\
\text { final feedback. I am glad this was done. It } \\
\text { gave order to the chaos. }\end{array}$ \\
\hline $\begin{array}{l}\text { Team } \\
\text { teaching }\end{array}$ & 27 & $\begin{array}{l}\text { Team teaching makes } \\
\text { lectures } \\
\text { conversational and } \\
\text { interesting and } \\
\text { provides multiple } \\
\text { perspectives. }\end{array}$ & $\begin{array}{l}\text { I really do like having two instructors in } \\
\text { the lesson. It helps to hold my interest and } \\
\text { seems more like a conversation than a } \\
\text { lecture. }\end{array}$ \\
\hline
\end{tabular}

A total of 568 students responded to the questions on what changes they would recommend being made to the video lessons. Among them, 209 (37\%) responded by saying the video lessons were excellent and that no changes were needed. Responses from 16 students were not relevant to the question. As a result, the remaining 343 responses were coded. Table 6 summarizes the three major changes students suggested be made. 
Table 6

What Changes Students Suggested Be Made: Code, Explanation, and Illustrative Note

\begin{tabular}{|c|c|c|c|}
\hline Code & Frequency & Explanation & Illustrative note \\
\hline $\begin{array}{l}\text { More } \\
\text { application } \\
\text { examples }\end{array}$ & 56 & $\begin{array}{l}\text { Provide more examples } \\
\text { of how concepts can be } \\
\text { applied and implemented. }\end{array}$ & $\begin{array}{l}\text { I would like to see more applied } \\
\text { examples of the topics in regards to } \\
\text { solving RPM problems. I think it } \\
\text { would have been nice to get more } \\
\text { guidance on how to apply these AI } \\
\text { learning concepts to our project. }\end{array}$ \\
\hline $\begin{array}{l}\text { More } \\
\text { exercises }\end{array}$ & 40 & $\begin{array}{l}\text { Provide more exercises, } \\
\text { especially more } \\
\text { challenging exercises, } \\
\text { and programming } \\
\text { exercises. }\end{array}$ & $\begin{array}{l}\text { The exercises are really helpful for } \\
\text { understanding the lecture. I think it will } \\
\text { be better if you can add more these } \\
\text { "hands-on" exercises. }\end{array}$ \\
\hline $\begin{array}{l}\text { More } \\
\text { depth } \\
\text { in } \\
\text { content }\end{array}$ & 36 & $\begin{array}{l}\text { Include more details } \\
\text { about the course topics in } \\
\text { the video lectures. }\end{array}$ & $\begin{array}{l}\text { Video lectures should contain more } \\
\text { information about concepts and more } \\
\text { examples to solidify the concept. I } \\
\text { would guess only a slightly more to } \\
\text { avoid them getting lengthier and } \\
\text { taxing. }\end{array}$ \\
\hline
\end{tabular}

\section{The Relationship Between Student Perceptions of the Video Lessons and the Course}

Simple linear regression was carried out to investigate the relationship between students' perceived effectiveness of the video lessons and the course. The effectiveness of the video lessons is measured by students' average rating of the four statements on the video lessons $(M=5.90, S D$ $=.96)$. Their rating of the course effectiveness ranges from 1 (bad) to 7 (excellent) $(M=6.00, S D$ $=1.04)$. The result revealed that their perceived effectiveness of the video lessons explained a significant portion of the variance in their perceived course effectiveness, $R^{2}=.401, F(1,1209)=$ $809.76, p<.001$. It was also found that the students' rating of the video lessons significantly predicted their rating of the course effectiveness, $\beta_{1}=.683, p<.001$. The regression equation was as follows: course effectiveness $=1.977+.683$ video effectiveness.

\section{Discussion}

The results of this study indicate that the video lessons designed with the seven-principle model in the online KBAI course were highly rated by students on the video lectures, the interactive exercises, the adaptive feedback from the intelligent tutors, and their overall value in helping students learn. Students' comments on the question regarding what they liked about the video lessons provide profound insights into their perceptions. The five major elements that students liked about the videos_video lectures, exercises and adaptive feedback, instructional structure, team teaching, and overall quality-have enabled us to attribute the perceived 
effectiveness to all the principles incorporated in the design model except the principle of learning through reflection. At the end of each video lesson, students were asked to reflect on and write down what they learned from the lesson. However, students did not always do it, as it was optional and was at the end of the video lesson. Students could easily exit the video lesson after studying it for an hour. However, those who did the exercise valued it, as one commented, "I took the Final Quiz of each lesson very seriously. Being able to articulate back the information in the lesson helped me to better retain that knowledge." To encourage students to do this exercise, instructors might take a few actions, such as communicating to the students the purpose and value of this exercise or providing certain incentives for completing it.

It is worth noting that the two practices that the instructors experimented with, team teaching and adaptive feedback, worked very well in this case. The team teaching not only makes the video lectures conversational and engaging but also provides multiple perspectives on the concepts and information presented. One student liked video lessons because "conversations and multiple perspectives in the videos were helpful. Also, the teaching style was great because the audience was asked quite a few questions throughout the lecture." This aligns with the suggestion that mixing first-person and third-person perspectives in instructional video may allow learners to be more engaged and improve learning (Boucheix, Gauthier, Fontaine, \& Jaffeux, 2018; Fiorella, van Gog, Hoogerheide, \& Mayer, 2017). The adaptive feedback was very well received by the students too. A student commented on it as follows: "Very good exercises in videos with useful feedback for incorrect answers. OMG this was so helpful because it often addressed why I would choose an incorrect answer." While it may take time and effort to develop adaptive feedback, it should be a good investment, as it has been proven that any practices without feedback would not help with learning (Fiorella \& Mayer, 2018), and adaptive feedback is particularly useful when learners need more than a correct/incorrect response (Johnson \& Priest, 2014).

The finding that students' perceptions of video effectiveness significantly predicted how they perceived the overall effectiveness of the course indicates that video lessons are vital to the success of an online course. This finding confirms what was found from a smaller scale study by Scagnoli, Choo, and Tian (2017), in which 94 graduate students participated in a survey, and the results indicate that their satisfaction with the course videos had a strong relationship with a positive overall learning experience. Although good course videos alone cannot guarantee the success of a course, courses that use videos with bad design and poor quality will more likely get poor ratings from students on the course as a whole. Therefore, to ensure learner satisfaction and enhance the online learning experience, it is vital that the instructional design and video production team be guided by established principles to create and produce effective videos. While there is no one-size-fits-all model, we hope the seven-principle model helps establish that the three core components, instructional methods, presentation, and sequence, should be integrated for designing and developing video lessons for online learning. When adopting this model, some principles could be modified as needed, because the selection of instructional methods depends on many factors, including subject matter, learning objectives, students, available technology resources, and so on.

While the feedback from the students on the video lessons was very positive, they also suggested some changes be made to the video lessons. We believe the suggestions result from students' different academic background and prior knowledge and skills. As the results of the demographic survey show, their programming experience was quite varied, which resulted in different learning needs, especially when they were working on assignments and projects that involved the application of skills. It may be feasible to add more examples, details, and exercises 
to the video lessons; however, we have to avoid — as students themselves pointed out — making the video lessons too "lengthy" or "taxing" by trying to cover everything and eventually losing the interest of those students who do not want any change. A strategy to achieve a balance while accommodating different needs is to provide resources outside of the video lessons for students who need them. Additional course supplement readings could help students explore related topics in more depth. Optional exercises could allow students to practice more. Case studies and project examples would enable students to get a clearer idea of how concepts are applied to real-world problems. The instructors have adopted some of these recommendations and added more learning materials to supplement the video lessons in more recent offerings of the online KBAI course.

\section{Limitations and Future Research}

There are a few limitations to this study. First, the study investigated student perceptions of the effectiveness of the videos lessons designed and developed based on a seven-principle model. The researchers in this study developed the model by integrating established principles of instructional design theories, and they evaluated it by gathering feedback from students enrolled in an online graduate class in computer science. They also informally discussed the model with colleagues at the university. However, the model has not been evaluated by experts outside of the university. Secondly, survey research was the primary method for the study. While survey is one of the commonly used methods to examine students' perceptions, it is worth noting that some research has cast doubt on the usefulness of course evaluations to assess course quality and learning outcomes (Uttl, White, \& Gonzalez, 2017), although earlier research found otherwise (Cohen, 1981). The large number of participants across eight semesters, high survey-response rate, and both quantitative and qualitative data may have raised the likelihood that the student evaluations are a useful outcome variable in this study. Nonetheless, the significant doubts raised regarding the reliability of student surveys in general imply that alternate evaluation measures ought to corroborate the findings of this study. Finally, we have not yet explored how students'

use of the videos lessons affects their learning performance. Future research studies can be conducted in this area by leveraging learning analytics on students' use of the video lessons. Studies on the effectiveness of this design model can also be expanded to disciplines other than computer science.

\section{Acknowledgements}

We are grateful to several people for their support for the development of the KBAI class, especially to our video producer Aaron Gross. We would also like to thank Dr. Jason Wang, who helped with coding the survey data. This research has been supported by several seed grants from the Georgia Institute of Technology. 


\section{References}

Aleamoni, L. M. (1978). Development and factorial validation of the Arizona Course/Instructor Evaluation Questionnaire. Educational and Psychological Measurement, 38, 1063-1067.

Bangert, A. W. (2006). The development of an instrument for assessing online teaching effectiveness. Journal of Educational Computing Research, 35(3), 227244. https://doi.org/10.2190/B3XP-5K61-7Q07-U443

Bimba, A. T., Idris, N., Al-Hunaiyyan, A., Mahmud, R. B., \& Shuib, N. L. B. M. (2017). Adaptive feedback in computer-based learning environments: A review. Adaptive Behavior, 25(5), 217-234. https://doi.org/10.1177/1059712317727590

Bonwell, C. C., \& Eison, J. A. (1991). Active learning: Creating excitement in the classroom. 1991 ASHE-ERIC higher education reports. Washington, DC: ERIC Clearinghouse on Higher Education, George Washington University.

Boucheix, J. M., Gauthier, P., Fontaine, J. B., \& Jaffeux, S. (2018). Mixed camera viewpoints improve learning medical hand procedure from video in nurse training? Computers in Human Behavior, 89, 418-429. https://doi.org/10.1016/j.chb.2018.01.017

Braun, V., \& Clarke, V. (2006). Using thematic analysis in psychology. Qualitative Research in Psychology, 3(2), 77-101. https://doi.org/10.1191/1478088706qp063oa

Chen, Q., Chen, Y., Liu, D., Shi, C., Wu, Y., \& Qu, H. (2016). Peakvizor: Visual analytics of peaks in video clickstreams from massive open online courses. IEEE Transactions on Visualization and Computer Graphics, 22(10), 2315-2330. https://doi.org/10.1109/tvcg.2015.2505305

Chorianopoulos, K. (2018). A taxonomy of asynchronous instructional video styles. The International Review of Research in Open and Distributed Learning, 19(1). https://doi.org/10.19173/irrodl.v19i1.2920

Clark, R. C., \& Mayer, R. E. (2016). E-learning and the science of instruction: Proven guidelines for consumers and designers of multimedia learning. Hoboken, NJ: Wiley.

Cohen, P. A. (1981). Student ratings of instruction and student achievement: A meta-analysis of multisection validity studies. Review of Educational Research, 51(3), 281-309. https://doi.org/10.3102/00346543051003281

Cortina, J. M. (1993). What is coefficient alpha? An examination of theory and applications. Journal of Applied Psychology, 78(1), 98-104. https://doi.org/10.1037/0021-9010.78.1.98

Cronbach, L. J. (1988). Internal consistency of tests: Analyses old and new. Psychometrika, 53(1), 63-70. https://doi.org/10.1007/bf02294194

d'Apollonia, S., \& Abrami, P. C. (1997). Navigating student ratings of instruction. American Psychologist, 52(11), 1198-1208. https://doi.org/10.1037/0003-066X.52.11.1198

De Koning, B. B., Hoogerheide, V., \& Boucheix, J. M. (2018). Developments and trends in learning with instructional video. Computers in Human Behavior, 89, 395-398. https://doi.org/10.1016/j.chb.2018.08.055

Dempsey, J. V., \& Sales, G. C. (1993). Interactive instruction and feedback. Englewood Cliffs, NJ: Educational Technology Publications.

Dewey, J. (1933). How the instructors think: A restatement of the reflective thinking to the educative process. Boston, MA: Heath. 
Feldman, K. A. (2007). Identifying exemplary teachers and teaching: Evidence from student ratings. In R. P. Perry \& J. C. Smart (Eds.), The teaching and learning in higher education: An evidence-based perspective (pp. 93-129). Dordrecht, The Netherlands: Springer.

Fiorella, L., van Gog, T., Hoogerheide, V., \& Mayer, R. E. (2017). It's all a matter of perspective: Viewing first-person video modeling examples promotes learning of an assembly task. Journal of Educational Psychology, 109(5), 653-665. https://doi.org/10.1037/edu0000161

Fiorella, L., \& Mayer, R. E. (2018). What works and what doesn't work with instructional video. Computers in Human Behavior, 89, 465-470. https://doi.org/10.1016/j.chb.2018.07.015

Goel, A., \& Joyner, D. (2016). An experiment in teaching artificial intelligence online. International Journal for Scholarship of Technology-Enhanced Learning, 1(1).

Goel, A., \& Joyner, D. A. (2017). Using AI to teach AI: Lessons from an online AI class. AI Magazine, 38(2), 48-58. https://doi.org/10.1609/aimag.v38i2.2732

Guest, G., MacQueen, K. M., \& Namey, E. E. (2011). Applied thematic analysis. London: Sage.

Guo, P. J., Kim, J., \& Rubin, R. (2014). How video production affects student engagement: An empirical study of MOOC Videos. Proceedings of the Second ACM Conference on Learning @ Scale. https://doi.org/10.1145/2556325.2566239

Hansch, A., Hillers, L., McConachie, K., Newman, C., Schildhauer, T., \& Schmidt, P. (2015). Video and online learning: Critical reflections and findings from the field. SSRN Electronic Journal. https://doi.org/10.2139/ssrn.2577882

Hollands, F. M., \& Tirthali, D. (2014). MOOCs: Expectations and reality. Full report. Center for Benefit-Cost Studies of Education, Teachers College, Columbia University, NY. Retrieved December 20, 2018, from https://files.eric.ed.gov/fulltext/ED547237.pdf

Johnson, C. I., \& Priest, H. A. (2014). The feedback principle in multimedia learning. In R. E. Mayer (Ed.), The Cambridge handbook of multimedia learning (pp. 449-463). Cambridge: Cambridge University Press. https://doi.org/10.1017/cbo9781139547369.023

Jonassen, D. H. (1999). Designing constructivist learning environments. In C. M. Reigeluth (Ed.), Instructional design theories and models: A new paradigm of instructional theory (Vol. II, pp. 215-239). Mahwah, NJ: Lawrence Erlbaum.

Kay, R. H. (2012). Exploring the use of video podcasts in education: A comprehensive review of the literature. Computers in Human Behavior, 28(3), 820-831.

https://doi.org/10.1016/j.chb.2012.01.011

Kim, J., Guo, P. J., Cai, C. J., Li, S., Gajos, K. Z., \& Miller, R. C. (2014a). Data-driven interaction techniques for improving navigation of educational videos. Proceedings of the 27th Annual ACM Symposium on User Interface Software and Technology-UIST '14. https://doi.org/10.1145/2642918.2647389

Kim, J., Guo, P. J., Seaton, D. T., Mitros, P., Gajos, K. Z., \& Miller, R. C. (2014b). Understanding in-video dropouts and interaction peaks in online lecture videos. Proceedings of the first ACM Conference on Learning @ Scale. https://doi.org/10.1145/2556325.2566237

Le, N. T. (2016). A classification of adaptive feedback in educational systems for programming. Systems, 4(2), 22. https://doi.org/10.3390/systems4020022 
Li, N., Kidzinski, L., Jermann, P., \& Dillenbourg, P. (2015). MOOC video interaction patterns: What do they tell us? In G. Conole, T. Klobučar, C. Rensing, J. Konert, \& E. Lavoué (Eds.), Design for teaching and learning in a networked world (pp. 197-210). Lecture Notes in Computer Science (Vol. 9309). Switzerland: Springer. https://doi.org/10.1007/978-3-31924258-3 15

Marsh, H. W. (1982). SEEQ: A reliable, valid, and useful instrument for collecting students' evaluations of university teaching. British Journal of Educational Psychology, 52(1), 77-95. https://doi.org/10.1111/j.2044-8279.1982.tb02505.x

Marsh, H. W. (1991). Multidimensional students' evaluations of teaching effectiveness: A test of alternative higher-order structures. Journal of Educational Psychology, 83(2), 285-296. https://doi.org/10.1037//0022-0663.83.2.285

Mayer, R. E. (2009). Multimedia learning (2nd ed.). New York, NY: Cambridge University Press.

Mayer, R. E. (2014). Principles based on social cues in multimedia learning: Personalization, voice, image, and embodiment principles. In R. E. Mayer (Ed.), Cambridge handbook of multimedia learning (2nd ed., pp. 345-368). New York, NY: Cambridge University Press. https://doi.org/10.1017/cbo9781139547369.017

Means, B., Toyama, Y., Murphy, R., Bakia, M., \& Jones, K. (2009). Evaluation of evidence-based practices in online learning: A meta-analysis and review of online learning studies. Washington, DC: U.S. Department of Education

Merrill, M. D. (2002). First principles of instruction. Educational Technology Research and Development, 50(3), 43-59. https://doi.org/10.1007/bf02505024

Merrill, M. D. (2007). First principles of instruction: A synthesis. In R. A. Reiser \& J. V. Dempsey (Eds.), Trends and issues in instructional design and technology (2nd ed., pp. 62-71). Upper Saddle River, NJ: Merrill/Prentice-Hall.

Moon, J. A. (1999). Reflection in learning and professional development: Theory and practice. London: Kogan Page.

Morgan, D. L. (2014). Integrating qualitative \& quantitative methods: A pragmatic approach. Thousand Oaks, CA: SAGE.

Morrison, G. R., Ross, S. M., Kalman, H. K., \& Kemp, J. E. (2012). Designing effective instruction (7th ed.). Hoboken, NJ: Wiley.

van Patten, J., Chao, C., \& Reigeluth, C. M. (1986). A review of strategies for sequencing and synthesizing instruction. Review of Educational Research, 56(4), 437-471. https://doi.org/10.3102/00346543056004437

Poquet, O., Lim, L., Mirriahi, N., \& Dawson, S. (2018). Video and learning: A systematic review (2007-2017). Proceedings of the 8th International Conference on Learning Analytics and Knowledge-LAK. https://doi.org/10.1145/3170358.3170376.

Prince, M. (2004). Does active learning work? A review of the research. Journal of Engineering Education, 93(3), 223-231. https://doi.org/10.1002/j.2168-9830.2004.tb00809.x

Reigeluth, C. M. (1999). The elaboration theory: Guidance for scope and sequences decisions. In C. M. Reigeluth (Ed.), Instructional-design theories and models: A new paradigm of instructional theory (Volume II, pp. 425-454). Mahwah, NJ: Lawrence Erlbaum. 
Reigeluth, C. M., \& Keller, J. B. (2009). Understanding instruction. In C. M. Reigeluth \& A. A. Carr-Chellman (Eds.), Instructional-design theories and models: Building a common knowledge base (pp. 27-39). New York, NY: Taylor \& Francis.

Santos-Espino, J. M., Afonso-Suárez, M. D., \& Guerra-Artal, C. (2016). Speakers and boards: A survey of instructional video styles in MOOCs. Technical Communication, 63(2), 101-115.

Scagnoli, N., Choo, J., \& Tian, J. (2017). Students' insights on the use of video lectures in online classes. British Journal of Educational Technology. https://doi.org/10.1111/bjet.12572

Seaman, J. E., Allen, I. E., \& Seaman, J. (2018). Grade level: Tracking online education in the United States. Babson Survey Research Group. https://onlinelearningsurvey.com/reports/gradeincrease.pdf

Sinha, T., Jermann, P., Li, N., \& Dillenbourg, P. (2014). Your click decides your fate: Inferring information processing and attrition behavior from MOOC video clickstream interactions. arXiv preprint arXiv: 1407.7131. https://doi.org/10.3115/v1/w14-4102

Sweller, J. (1988). Cognitive load during problem solving: Effects on learning. Cognitive Science, 12(2), 257-285. https://doi.org/10.1207/s15516709cog1202_ 4

Teddlie, C., \& Tashakkori, A. (2009). Foundations of mixed methods research: Integrating quantitative and qualitative approaches in the social and behavioral sciences. Thousand Oaks, CA: SAGE.

Theall, M., \& Feldman, K. A. (2007). Commentary and update on Feldman's (1997) "Identifying exemplary teachers and teaching: Evidence from student ratings." In R. P. Perry \& J. C. Smart (Eds.), The teaching and learning in higher education: An evidence-based perspective (pp. 130-143). Dordrecht, Netherlands: Springer.

Uttl, B., White, C., \& Gonzalez, D. (2017). Meta-analysis of faculty's teaching effectiveness: Student evaluation of teaching ratings and student learning are not related. Studies in Educational Evaluation, 54, 22-42. https://doi.org/10.1016/j.stueduc.2016.08.007 